\title{
Application of TBLT in Primary School Classes--A Case Study of the Fourth Primary School in Awati County
}

\author{
$\mathrm{Li} \mathrm{Ma}^{1}$ \\ ${ }^{1}$ Independent Researcher, Nanchong, China \\ Correspondence: Li Ma, Independent Researcher, Nanchong, Sichuan, China.
}

Received: September 1, 2019

doi:10.20849/aes.v4i2.656
Accepted: September 24, $2019 \quad$ Online Published: October 9, 2019

URL: https://doi.org/10.20849/aes.v4i2.656

\begin{abstract}
As a national event, education is important issue, which has an influence on thousands of generations. How to teach students to learn knowledge and apply it at the same time has turns out to be a challenging work for numbers of teachers. To solve this problem, some inspiration could come from a method founded in 1980s, which is also called Task Based Language Teaching. As its key characteristics, TBLT makes students learn the knowledge through using the knowledge. In particular, taking execution and communicating interactively are explored as the method to achieve the language learning. This paper investigates the application of the TBLT in the Fourth Primary School in Awati County of Xinjiang. Problems existing in the implementation process are revealed and the underlying causes are analyzed. The results of this study can provide reference for other teachers to use task-based teaching method in the future.
\end{abstract}

Keywords: tasked based language teaching, primary education, the fourth primary school of Awati

\section{Introduction}

Since the traditional teaching model "practice-oriented" transitions to the newly model "function-oriented", the teaching focus also switches to communicative competence from the original linguistic competence. As a foreign language teaching method widely recognized and accepted by linguists and teachers, Task Based Language Teaching (TBLT) based on the principle of "Learning by Doing" has been built for nearly 30 years. Based on the theory of language acquisition, social construction, and curriculum theory, TBLT emphasizes how to master a foreign language by communicative activities. This teaching method fully develops learners' cognitive ability by participating, experiencing, interacting, communicating and cooperating, carrying out two education ideas: "student-centered" and human-oriented". Therefore, TBLT is worth being promoted as an effective foreign language teaching method. In recent years, more and more teachers begin to concern it. And here come the days of TBLT in applied linguistics. Meanwhile, primary education is the initial stage for English learners in China, the same as the critical period for language acquisition. During the period, applying Task Based Language Teaching appropriately plays a significant role in cultivating students' sense of language, improving the ability of listening and speaking and further enhancing comprehensive ability However, due to the different views of the academic circles on the definition of TBLT, it is unclear about the effectiveness of TBLT in the classes of primary school. In reality, the application of Task Based Language Teaching is only limited to acting or answering questions in class after adequate preparation, which is contrary to the concept of TBLT. Therefore, it is significant to study the application of TBLT in the classes of primary school (Ellis, 1994).

This paper includes five chapters. The first chapter is introduction and the second chapter outlines the concepts and features on TBLT. An analysis on the rules of TBLT in primary school classes is written in the third one. The author analyses the problem from three aspects: attach the same weight on form and function, design exercisable tasks and combine with traditional teaching method. In the fourth chapter, the author takes the case of the Fourth Primary School in Awati County for an example to show the reality on application of TBLT. The argument comes from two aspects: teaching process and teachers' interpretation on TBLT. At last, the author summarizes the whole paper in the conclusion.

\section{Overview of TBLT}

In this chapter, the concept and the features of TBLT are introduced in turn. It is very helpful for further study by interpreting them. 


\subsection{Concept of TBLT}

TBLT is a teaching way based on tasks. In every teaching stage, the foundation "task" plays an important role (Cheng, 2004).

Teachers should organize teaching with tasks and help students achieve their overall recognition by fulfilling tasks. After arousing their interest, let them put target language into practice by apperceiving and cognizing them. Only by practicing language in experience can the target of Task Based Language Teaching achieves and students' language ability improves. The based theory of Task Based Language Teaching is in accordance with constructivism. According to the relative theory, the essence of constructivism emphasizes the facticity and cooperation of tasks. After all, students should be the real subject during the learning process of foreign language. Through exercising a large number of words, new knowledge and experience are constructed. TBLT puts an emphasis on combining syllabus design with teaching method. To embody the educational idea "students' development-oriented", tasks run through the whole process of TBLT, which blend as well as humanity of teaching content and target and richness of teaching environment (Mu, 2008).

\subsection{Features of TBLT}

To sum up, the features of TBLT consist of four aspects. Firstly, students complete second-language communication by various tasks in TBLT, thus enhancing communicative skill. Secondly, add real linguistic materials in class teaching, enabling students understand and utilize language easily and quickly. Thirdly, teaching target should be divided into several tasks which can be finished by students under teachers' help for the achievement of overall teaching objective. The last but not the least, in TBLT class, students act communicators, teachers act assistants, organizers, supervisors and participants as well (Fang, 2003).

\section{Primary School Classes' TBLT Rules}

Whether Task Based Language Teaching can be applied successfully in primary school class, the key step is to combine it with primary school teaching features and realize the best teaching effectiveness. According to the obvious features in English classes of primary schools and the main teaching ideas of TBLT, the author summarizes some rules in the application of primary schools classes' TBLT as follow, so as to make better use of it in the actual teaching process (Richards, \& Rodgers, 2008).

\subsection{Lay Equal Stress on Form and Function}

TBLT belongs to system-functional linguistics, aiming at improve learners' communicative competence. However, the general feature throughout the whole primary school English teaching stage is that the students' English foundation is relatively weak and their basic knowledge is extremely limited. Their linguistic skills need to be improved whether the quantity and quality of vocabulary or the use of grammar. In addition, students also lay much stress on English knowledge, to some extent, which is just the advantage in doing formal exercises. By investigation and study, the author finds that although pupils like English class activities very much, apart from listening and speaking activities, they also would like to gain both sentiments and language knowledge which should cover certain respective proportion. In other words, TBLT activities need to combine form and function in English class. Teachers should be advised to teach according traditional functional linguistics while strengthen practices in form. Function is held essential with form as a supplement, pitching into each other (Xia, 1998).

\subsection{Design Exercisable Tasks}

Whether the task is exercisable or not is an important factor for the success of English classes' activities. Teachers should pay attention to combine tasks with learning materials and guarantee that tasks can be exercisable (Gao, 2007).

Tasks should be neither too difficult nor too easy. If the task is too difficult, learners would feel anxious. In reverse, too easy tasks could make learners feeling boring. That is to say, the tasks should be designed to take full account of students' English skill level. Due to the limited accumulation of pupils' English knowledge and the idea that English learning is regarded to learn a foreign language than a second- language, task design must be closely integrated with students' learning content, which can promptly gain students' feedback in class. Meanwhile, in order to promote students to learn more deeply and keep enthusiasm for learning, tasks should be certain level of difficulty (Peng, 2010).

\subsection{Combine With Traditional Teaching Method}

Task Based Language Teaching should be combined with traditional teaching method so as that it can take advantage of compromise.

At present, TBLT is a very popular foreign language teaching method, but it does not mean to exclude other 
teaching methods, especially the traditional teaching methods represented by Grammar - translation method. Skehan (1998) pointed out that TBLT focuses on meaning, which leads to underestimate formal exercises to some extent, while the difficulty of TBLT is how to put an emphasis on formal exercises without influencing the communicative naturalness aroused by tasks so as to promote the development of inter-language (Skehan, 1998). It can meet the need of primary students, who are lack of vocabularies and basic knowledgement. While, their grammar structure is supposed to be promoted.

Although students can do formal exercises by completing communicative tasks, it is not enough for pupils who are in the initial stage of English learning. According to the relative study, no doubt that it would be effective to combine fluency and accuracy, but the traditional teaching method mainly focusing on form still plays an important role. Traditional foreign language teaching methods take the advantages of logical explanation, plenty of formal exercises and rapid effect on improving grades. The advocates of TBLT do not deny the profits and proficiency of traditional teaching method. The integration of two side, traditional teaching method, which pays emphasis on acquisition of pure language knowledge, the other TBLT, Which make most of appropriate tasks and language skills. The counterbalance of two lead to a more efficient way. Primary students can rely on it to get greater language skills. Therefore, the compromise between traditional teaching method and TBLT would make them complement each other better in teaching, thus achieve better teaching effect (Zou, Chen, Shi, \& Zhang, 2006).

\section{Case Study of the Fourth Primary School in Awati County}

The Fourth Primary School was built in Awati County in 2000. There are 32 classes and the total number of students is over three thousand. In this chapter, the author takes it as an example to study the application of TBLT

\subsection{Teaching Process}

Teaching process is the key process for any teaching method. It would be divided into three parts: teaching in class, review after class and daily work.

\subsubsection{Teaching in Class}

Class teaching is in the front line of the application of TBLT. In order to know the practical application of TBLT, the author has made a detailed investigation on the class teaching for nearly one semester in the Fourth Primary School, which is in Awati County, Aksu Prefecture, Xinjiang Uygur Autonomous Region.

The Fourth Primary School is a demonstration school among the local schools. This school aims at improving teaching quality and training minorities for profession. At the present, the Fourth Primary School offer English classes from the third year and no English lessons are offered in the first and second grades. Third-year students are at the initial stage of English learning. Most of the third-graders know little English when they begin to learn English. So their English level is on the threshold. The fourth-graders studied English textbooks edited by the school in the first and second grades and in the third grade they changed to the textbooks edited by People's Education. The fourth-graders are in the "transitional period" of English learning. By learning two years' school textbooks and one year's People's Education textbooks, students are gradually establishing their own perception and comprehension to English learning. The fifth and sixth-graders have learned the school's textbooks in a systematic way from the first grade, forming the fixed learning habits and methods in some detail and accumulating a certain amount of English words and sentences. No doubt that it is more suitable to apply TBLT for the fifth and sixth-graders Therefore, the author determines that the subject of study is the fifth and sixth-graders. The author makes a questionnaire survey on three class' students of the fifth and sixth grade, choosing two classes A and B from the fifth grade and one class C from the sixth grade. The average score of Class A is higher than that of Class B. The average score of Class C in the sixth grade is similar to that of Class A in the fifth grade. A total of 188 questionnaires are sent out and 164 valid questionnaires are collected. The results of the questionnaires achieve the desired result. Students' answers to the question "Will the teachers help you learn and review knowledge by assigning tasks related to real life in English class?" are shown in Table 1.

Table 1 . How frequently tasks are used in class

\begin{tabular}{ll}
\hline Option & Proportion (\%) \\
\hline Regularly & 22.8 \\
\hline Occasionally & 40.5 \\
\hline Rarely & 36.7 \\
\hline
\end{tabular}


After the choice question, the author assigns a subject one, which asks students to give some examples related to exercisable task or knowledge's review. When analyzing the answers, the author finds that some students cannot take any examples, while other students take those unrelated to TBLT. For example, some students state that teachers would help them recite words and assign some tasks on reading or reciting texts.

At the same time, teachers are asked to fill a questionnaire. The survey results on "Is it necessary to utilize TBLT in class?" are as follows:

Table 2. Is it necessary to utilize TBLT in class

\begin{tabular}{ll}
\hline Option & Proportion (\%) \\
\hline Affirmative & 24.1 \\
\hline Depend on teaching content & 75.9 \\
\hline Negative & 0 \\
\hline
\end{tabular}

The survey results show that majority of teachers in this school would like to apply TBLT in their classes. However, by observing in class and analyzing the survey result of students' answers, it can be seen that more than $30 \%$ of students seldom identity TBLT in learning process, while others think they have been taught by TBLT, but they make wrong comprehension on TBLT. As a result, the effectiveness of TBLT application remains to be improved in the fourth primary school in Awati County.

\subsubsection{Review After Class}

Besides being applied to teach new knowledge, Task Based Language Teaching can also help to review and strengthen the learned knowledge. The answers about what kind of method do you adopt during reviewing learned contents are showed in Table 3.

Table 3. What kind of review methods do you adopt

\begin{tabular}{ll}
\hline Option & Proportion (\%) \\
\hline Review words and sentences separately & 27.0 \\
\hline Sum up knowledge types: time; place... & 21.2 \\
\hline $\begin{array}{l}\text { Review according to unit subject: traveling; } \\
\text { family party... }\end{array}$ & 42.5 \\
\hline No regular methods & 9.3 \\
\hline
\end{tabular}

From these data, we can find that nearly half of the students choose to review in the order of unit subject, which certificates that the students think it is helpful to review the unit subjects for improving scores. For example, when students review knowledge points related to the travel subject, they will imagine how to use the words and sentences learned in a certain scene if they go to travel by themselves one day. This idea of "learning for practice" would help students classify the knowledge in the scene; so as to they can memory knowledge easily in real life. When analyzing the answer of what method do you often use to guide students to review, a questionnaire survey of English teachers in the Fourth Primary School indicates that almost all teachers take the way of guiding students to read and recite texts as the main review method. Some teachers also add some other forms in the process of review, such as translation, analysis of test paper, doing some simulation test and so on. In addition, one teacher even more emphasizes that learning words and key sentences' forms should be the main content of review. Compared with the idea of students' situation-oriented and application-oriented review method, teachers are inclined to take it into account from the mastery of structural knowledge when making review plans, less considerate the functionality and communicative of language.

\subsubsection{Daily Practice}

The object "Learning by doing" decides the application scope of TBLT. Not only in class learn under teachers' guide, but also after class students can experiment by themselves, making use of several of learning sources in life. As a result, the concept of Task Based Language Teaching should not just be applied in class learning but in daily practice (Nunan, 1989). The English homework of the Fourth Primary School mainly includes reciting words, writing sentences, doing exercise books, training special listening, speaking, reading, writing and etc. 
About the questionnaires as follows: "What other new tasks teachers would assign besides routine ones including writing words and doing exercise books?" "Do you feel the connection of tasks and your life?" "Do you like these tasks?" and etc. The survey result shows that some students take some new formal tasks for example: watching English movies and doing homework by computes or mobile phones. But such homework has not any connections with life. Other students illustrate some homework more close to life, such as writing a letter or postcard in English, sending an E-mail in English, speaking the furniture name of house, making a travelling plan and acting small plays in English, etc. If teachers assign more homework related life practice, students would be more active to finish them.

By observing teachers' answer of the question "What homework can train students' language competence under current situation?" Their answers concentrate on three kinds: English paper, comprehension test and dubbing in English. In the survey, some teachers say that much homework may base on consolidating the knowledge learned in class and training students' language skills: listening, speaking, reading and writing. The survey result shows that the teachers of the Fourth Primary School still facilitates some traditional training tasks when training students' language competence, though they occasionally think about the link between English learning and practice and how to create new homework in form.

\subsection{Teachers' Interpretation on TBLT}

This chapter includes two parts. The first part introduces teachers' interpretation on TBLT and the next part is about the presentation and control of tasks.

\subsubsection{Teachers' Interpretation on the Theory}

In order to know about the learning situation on TBLT in the Fourth Primary School, the author makes a questionnaire of English teachers. All of those teachers own bachelor degrees or above. Three teachers of all have over ten years' teaching experience, while others also have taught English for five years, less than ten years. Among them, there is one senior elementary teacher and one first-degree teacher. The rest are second-degree elementary teachers. From the above introduction, we can conclude that the teachers of the Fourth Primary School have been educated well in general.

The answers of "Have you studied Tasked Based Language Teaching?" are shown in the next table.

Table 4. Have you studied tasked based language teaching

\begin{tabular}{ll}
\hline Option & Proportion $(\%)$ \\
\hline Be interested in it, read relative papers & 52.1 \\
\hline Know the method, kind of understanding & 47.9 \\
\hline Contact it less & 0 \\
\hline
\end{tabular}

As seen in the above table, above fifty percent of teachers choose the option "Be interested in it, read relative papers and about forty percent of teachers choose the option "Know the method, kind of understanding". The survey result shows that this school's teachers can actively concern TBLT in daily teaching owing to their good educational background. However, not all the teachers have high enthusiasm on TBLT. Take an example. One teacher applies TBLT in class by such practice: When teaching words and sentences, she will give students models and time to complete tasks. The fault of the practice lies in mixing the concept of exercises and tasks because the words and sentences exercises are based on linguistic form. It certificates that teachers of the Fourth Primary School still deepen their comprehension on TBLT.

\subsubsection{Presentation and Control of Tasks}

Task Based Language Teaching provides a kind of teaching idea, under whose guide teachers design teaching activities with tasks in form. At the same time, teachers should concern two aspects in the process of implementing tasks. Firstly, the detailed illustration and guide is needed when presenting tasks. Next, when students are implementing tasks, teacher should change and control tasks in time by observing students' uses of target language and task completion carefully (Xing, \& Luo, 2014).

By making an observation on English teaching in the Fourth Primary School, the author finds that the tasks presented by teachers are not detailed enough and are not effective in time. In the teaching activity "Design a postcard", the teachers' target is to help students review how to use preposition "in, on, at" to express time. The author collects all of the postcards designed by some students in a class for analysis, finding that the postcards are all equipped with beautiful pictures and clear subjects, such as "Friendship", "Family" and "City". But these 
postcards are only written with time but no places by students. Because the prepositions of expressing time are just learned, many students can accurately complete the time expression, such as "on Saturday", "at the afternoon", "in March". Obviously the postcard is not complete owing to the lack of places. In addition, a complete postcard should also include addressee's name and benediction. Some defects exist in the link of presentation, which is why students are failure to design a complete postcard.

In one teacher's lesson subjected by football and basketball, students are required to finish a dialogue under the situation of sports store. The aim of the dialogue is to help students review learned knowledge. Actually, the author found that some students were watching the sentence examples in power point and did not have any contact and interaction by sight during the whole dialogue. Questions and answers were also stated according to the examples. In addition, students cannot communicate according to their realities. This process is just like two actors' reading training rather than inquiring each other on the name of sports articles. In the process of giving lessons, teachers did not instruct students from reading to speaking in time. On the process of discussing and analyzing the classes, teachers also did not concern the problem either.

\section{Conclusion}

By investigating and studying the application of TBLT in the Fourth Primary School in Awati County, Aksu Prefecture, Xinjiang. This paper reveals the existing problems of TBLT and summarizes the causes of the problems, so as to make further improvements and create more suitable methods for students' language learning. The innovation of this paper lies in the combination of data analysis and text survey, which can reveal the problems as a whole. And the results of research can also be more valuable for reference. In addition, this study only takes the teaching situation of one primary school as an example to explore the actual application of TBLT, which has certain limitations for reference. The author hopes that more scholars will go to different schools to investigating the application of TBLT, so as to help TBLT implemented in an effective way.

\section{References}

Cheng, X. (2004). Task-Based Language Teaching. Beijing: Higher Education Press.

Ellis, R. (1994). The Study of Second Language Acquisition (pp. 638-645). Oxford: Oxford University Press.

Fang, W. (2003). A Vertical and Horizontal Discussion of Task-Based Teaching Approach of Foreign Languages. Foreign Languages and Their Teaching, (9), 17-20.

Gao, S. (2007). Limitations of Task-Based Foreign Language Teaching. Central China Normal University Journal of Postgraduates, (2), 48-51.

$\mathrm{Mu}$, X. (2008). A Preliminary Exploration of Animation Teaching of Primary School English Classroom. Southwest University, (5).

Nunan, D. (1989). Designing Tasks for the Communicative Classroom. Cambridge: Cambridge University Press.

Peng, Q. (2010). An Analysis of Dilemma in Development of Task-Based Teaching of Primary School English Under the Background of New Curriculum. Journal of Elementary Education College of Tianjin Normal University, (2), 93-94.

Richards, J. C., \& Rodgers, T. S. (2008). Approaches and Methods in Language Teaching (p. 468). Beijing: Foreign Language Teaching and Research Press.

Skehan, P. (1998). A Cognitive Approach to Language Learning. Oxford: Oxford University Press. https://doi.org/10.1177/003368829802900209

Xia, J., \& Kong, X. (1998). Theoretical Basis and Comparison of the Two Models of the "Teaching Approach of Problems" and "Task-Based Teaching". Foreign Language World, (3).

Xing, J., \& Luo, S. (2014). Review of "Task-Based Language Teaching under a Circumstance of Foreign Languages: Research and Implementation". English Studies, (3), 81-84.

Zou, W., Chen, S., Shi, T., \& Zhang, S. (2006). A Study on the Model of English Classroom Teaching at the Stage of Compulsory Education in Shanghai. English Teaching and Research in Elementary and Secondary School, (1), 1-6.

\section{Copyrights}

Copyright for this article is retained by the author(s), with first publication rights granted to the journal.

This is an open-access article distributed under the terms and conditions of the Creative Commons Attribution license (http://creativecommons.org/licenses/by/4.0/). 